\title{
Hellas as a Possible Site of Ancient Ice-Covered Lakes on Mars
}

\author{
Jeffrey M. Moore \\ Space Science Division, NASA Ames Research Center, MS 245-3 \\ Moffett Field, CA 94035
}

and

Don E. Wilhelms

Astrogeology Branch, U.S. Geological Survey (Retired)

P. O. Box 595, Monte Rio, CA 95462

37 Pages

12 Figures

Submitted: 31 January 2001

Revised: 9 July 2001 


\begin{abstract}
Based on topographic, morphologic, and stratigraphic evidence, we propose that ancient water-laid sediment is the dominant component of deposits within Hellas Planitia, Mars. Multiply layered sediment is manifested by alternating benches and scarps visible in Mars Orbiting Camera narrow-angle (MOC NA) images. Viking Orbiter camera and MOC NA images were used to map contacts and stratigraphically order the different materials units within Hellas. Mars Orbiting Laser Altimeter (MOLA) data reveal that the contacts of these sedimentary units, as well as a number of scarps or other abrupt changes in landscape texture, trace contours of constant elevation for thousands of $\mathrm{km}$, and in one case all around the basin. Channels, consensually interpreted to be cut by water, lead into the basin. MOLA results indicate that the area encompassed by greater Hellas' highest closed contour is nearly one-fifth that of the entire northern plains, making the Hellas "drainage" area much larger than previously reported. If lakes formed under climatic conditions similar to the modern Martian climate, they would develop thick ice carapaces, then the lakes would eventually sublimate away. Two units within Hellas exhibit a reticulate or honeycomb pattern we speculate are impressions made by lake-lowered ice blocks grounding into initially soft mud.
\end{abstract}


Strom (1992) suggested that all the deposits and landforms of Hellas Planitia originated

from continental-style glaciers and proglacial lakes. Moore and Edgett (1993) considered volcanic airfall, loess, lacustrine sediment, and some types of volcanic mudflows (but not coarse glacial deposits or blocky volcanic flows) to be consistent with data on particle size inferred from the Viking Infrared Thermal Mapper and Earth-based radar (Butler et al., 1993). Tanaka and Leonard (1995) concluded that the bulk of Hellas basin floor deposits were aeolian in origin.

\section{Perspective and Approach}

This study began, several years prior to Mars Global Surveyor (MGS) orbit insertion, as Viking-based geologic mapping of the northwest portion of the basin between $37.5^{\circ}$ and $42.5^{\circ} \mathrm{S}$, and $300^{\circ}$ and $315^{\circ} \mathrm{W}$ (Moore and Wilhelms, 2001). This paper adds observations beyond that original map area to encompass the entire Hellas region (Figs. 1, 2, 3). Elevation and image data obtained recently by $M G S$ both amplify and modify the original study

We made several assumptions. The first is implicit in the mention of the results of Moore and Edgett (1993), who inferred various properties of the uppermost material covering Hellas Planitia based on its thermal inertia. Thermal inertia is useful in deriving uppermost surface-particle sizes only if those particles are not larger than the diurnal skin depth: effectively no more than a few mm on Mars (Jakosky, 1986). Surfaces exhibiting the very lowest thermal inertia are constrained to be dust (e.g., Kieffer et al., 1977; Mellon et al., 2000). Intermediate thermal inertias, like those for Hellas Planitia, are 
multiple working hypotheses, no matter how wrong they later prove to be, because purely inductive mapping has seldom been productive (Wilhelms, 1990). However, the experience of terrestrial field geology strongly indicates the results of non-ground-truthed image-based geologic mapping are tentative and, at best, the equivalent of hypotheses. Nevertheless, until ground truth can be acquired, traditional planetary geologic mapping remains at least a very useful mechanism for organizing observations and presenting results (Wilhelms, 1990).

As noted by Malin and Edgett (2000a), the terrains of Mars very often appear surprisingly different at the meter-scale as seen in images from the narrow angle (NA) instrument of the Mars Orbiter Camera (MOC) than they do in images at hectometerscale resolution from the Viking Orbiter cameras or the MOC wide angle (WA) camera. Malin and Edgett (2000a) further point out that many Martian meter-scale features defy explanation on the basis of terrestrial analogs and field experience. Part of our job, therefore, was to interpret the (unfortunately widely scattered) MOC NA images within the Martian context furnished by the contiguous imaging at the hectometer scale. One challenge is to distinguish depositional from erosional features. Malin and Edgett (2000b) observe that exhumation of older surfaces on Mars is more widespread than previously thought by most workers. Continuous deposits once consensually interpreted to be subsequent deposition within topographic lows are now seen in MOC NA images to be, in fact, older surfaces exposed in erosional windows. We conclude, as did Moore and Edgett (1993), that much of Hellas Planitia has undergone widespread erosion. Consequently we took special care in inferring stratigraphic relations. 
We speculate that observed stratigraphic and topographic relations imply at least one - relatively well-defined stand of an ice-covered lake, along with additional possible stands at other elevations. While we find this hypothesis bore up better during our study than others that we initially considered, we certainly accept that it, as an explanation, is not conclusive.

\section{Observations and Inferences}

In this section, we will describe textures, landforms, suites of landforms, the relationship of these features to inferred units, and the relationships among units seen in contiguous Viking Orbiter images and in select MOC NA images that illustrate the characteristics of various relevant landscapes at meter scale. In addition to inferring the relationship of landforms to materials units, we infer (or interpret) some of the basic intrinsic properties of materials that compose landforms (e.g., they are layered, susceptible to erosion by wind abrasion, etc.).

The mountainous and less rugged materials of the Hellas basin rim are not considered per se in this report because they predate the materials that are relevant to this study. The number of large craters superposed on the basin rim clearly demonstrates an age of Early Noachian, the oldest epoch of Martian history (e.g., Greeley and Guest, 1987; Tanaka and Leonard, 1995). Most of the Hellas Planitia materials within the Hellas basin have been assigned ages at the Noachian-Hesperian transition or in the Early Hesperian (Greeley and Guest, 1987; Tanaka and Leonard, 1995; Leonard and Tanaka, 2001). However, crater statistics on which such dates have been based are probably not 
Unit $\mathrm{m}$ is dissected in many places by small channels (Tanaka and Leonard, 1995). Eroded surfaces of unit $\mathrm{m}$, where seen in MOC NA imaging, reveal alternating scarps and benches inferred to manifest layering (Fig. 4). The inferred layers exhibit little variation in thickness from one to another and are stacked in large numbers.

A conspicuous circumferential deposit along the western margin of Hellas Planitia forms an extensive, discontinuous annular band of reticulate material (unit $r$ ) along the inward-sloping periphery (Figs. 5, 6). Reticulate material appears superposed on unit m. It is characterized by sharp interconnected ridges generally tangential or normal to the basin rim and enclosing rectangular or elliptical depressions. Individual "cells" enclosed by the interconnecting ridges are typically $1-2 \mathrm{~km}$ across, though some are smaller. Ridge crests range from rounded to sharp. The floors of the cells are often flat, though some are crossed by smaller quasi-parallel ridges. This material shows no obvious evidence for layering.

A plains-forming material (unit p; Fig. 5), abuts and encroaches on unit $r$ and surrounds the deposits of the large central plateau informally named by us after Alpheus Colles (unit pl; Fig. 1). This plains unit is smooth to wavy, and thick enough to bury older topography. It is traversed by wrinkle ridges (Tanaka and Leonard, 1995). We interpret unit $\mathrm{p}$ to postdate the Alpheus Colles plateau deposits, giving it an early Hesperian age, as do Leonard and Tanaka (2001) for what we conclude is the same unit surrounding the eastern border of the Alpheus Colles plateau (Fig. 1). The expansive exposure of unit $\mathrm{p}$ in the eastern part of the basin is not grossly eroded. However, it is undermined at a few localities (Figs. 1, 3b, 3c) by a chaos-forming process that has also operated to degrade the older Alpheus Colles plateau, implying that Alpheus Colles 
probably a minimum age because the evident erosion presumably has destroyed some craters. Stratigraphic relations suggest that unit $\mathrm{pl}$ is among the oldest post-basin deposits, possibly contemporaneous with unit $\mathrm{m}$. Retreat of the west, northwest, and northern margins of the plateau is suggested by their abrupt truncation; streamlined scarps in the north suggest wind erosion as the cause (see scarps right of w in Fig. 3a). Plains material (unit p) occupies the surface below and against the retreated scarps, indicating an old age for the plateau and the putative retreat. In the east, the plains overlap the plateau (Figs. 3b, 3c).

The interior of the Alpheus Colles plateau contains many enclosed depressions whose floors are covered with chaotically arranged blocks (Figs. 3c, 3d, see location of Hellas Chaos in Fig. 1) similar to chaotic terrain seen elsewhere on Mars (e.g. Sharp, 1973). If chaotic terrain within Alpheus Colles is formed by collapse, then its presence implies a thoroughgoing undermining and removal of support. The knobs of this chaotic material are, in many localities, closely spaced or touching, and most are roughly equidimensional and similar in size. These properties suggest an origin as broken, downdropped, and rotated blocks of the plateau, resulting from chaotic collapse inferred to be caused by loss of interstitial ice in an initially ice-rich substrate (e.g., Sharp, 1973; Carr, 1996). Though we assume that chaotic terrain within Hellas most likely formed through loss of ground ice, some of it could be simply an old, exhumed, knobby or butte-covered surface. Knobs in some localities are elongated and oriented northeast-southwest (see knobs left of $y$ in Fig. 3d). We speculate that these knobs may have been modified by wind erosion into elongate features and can therefore be classified as yardangs (see also Tanaka and Leonard 1995). Aeolian modification does not, however, necessarily imply 
reminiscent of originally horizontally stacked material subjected to plastic deformation. A search by the authors and by an organized group of volunteers (Kanefsky et al., 2001) for examples of this particular "honeycomb cell" landscape elsewhere on Mars has so far had negative results. Kargel and Strom (1992) mapped honeycomb material as "kettle or ice stagnation topography." Tanaka and Leonard (1995), called it the "reticulate ridge unit," and saw an analogy with compound crescentic dunes, but MOC NA images refute this interpretation (Fig. 11). The mechanical coherence necessary to maintain the observed morphology of the pit (or "cell") septa excludes a loose-sand constitution. Moreover, the morphology seen in MOC NA images is unlike any known dune form. Also present are strongly angular hectometer-sized ridge-bounded polygons seen among the kilometer-scale "cells" (Figs. 11 and 12). These hectometer-scale ridge-bounded polygons dominate the scene in Figure 12, which is located near the periphery of unit h, though in other images of unit $h$ (including the northern part of the full image of Figure 12, left insert), the cells are dominant. Tanaka and Leonard (1995) crater-date honeycomb material as the youngest of all units discussed in our study, and we agree because it appears to be superposed on all neighboring units. A good example of unit $h$ appears to sit unconformably on unit pl in Figure 8. As honeycomb material appears to embay the west and northwest margins of unit $\mathrm{pl}$, which probably retreated, our stratigraphic placement of honeycomb material implies that it was deposited after this retreat took place.

Recently acquired topographic data from the Mars Orbiter Laser Altimeter (MOLA) aboard MGS has allowed us further to relate and characterize the units mapped in the study area. There is a concordance of landforms and deposit contacts along the 


\section{Speculation and Hypothesis}

The layered appearance of the Hellas Planitia materials that is evident in both Viking and MOC NA images indicates sedimentary deposits of some sort. The alternating benches and scarps along deposit contacts, the collapse into chaos, and the truncated scarps and isolated knobs of the plateau strata indicate susceptibility to erosion. So, why do we favor standing water under a thick ice carapace as the main agent of deposition and bedform modification? To support this admittedly speculative hypothesis we will consider possible explanations for the landforms and the inferred materials units just described in the previous section.

The best evidence for deposition from suspension in water comes from the correlation of landforms and deposits all along the basin periphery at about $5.8 \mathrm{~km}$ below, and to a lesser extent about $3.1 \mathrm{~km}$ below the MOLA-derived Mars datum. These "bathtub rings" may indicate that the Hellas basin was once filled by water, at different times, to these depths. For instance, the change in morphology of the large eastern channels, Dao and Harmakhis Valles, from prominent, sharp, and exposed (above), to diminished, muted, and partly buried by unit $\mathrm{p}$ below the $-5.8 \mathrm{~km}$ contour resemble terrestrial marine channels beyond the mouths and sedimentary deposits of large rivers (e.g., Damuth et al., 1988). Kargel and Strom (1992) also noted this change in stream morphology and attributed it to the interaction of water flowing from channels into a lake. The base of the nearly $1000 \mathrm{~km}$ long scarp across which this change in channel expression occurs is at a constant elevation of about $-5.8 \mathrm{~km}$, at the same elevation as the belt of unit $r$ and the outer periphery of unit $p$. We are not proposing that these scarps are wave-cut shore cliffs, but we speculate that they instead mark a boundary that may have 
through many cycles, and thus mark events that were much more frequent and cyclic than the ones indicated by the putative stillstands (e.g., at -3.1 , and $-5.8 \mathrm{~km}$ ). On Earth, this rhythmic modulation is usually due to variations of climate, such as the annual seasons. Deposits with layers of irregular thickness (such as unit pl) imply surges of deposition triggered by random events. Random events can certainly transport material by means other than water. Repeated seasonal variations in an aeolian regime could produce rhythmic deposition. However, the observation that these deposits occur at constant elevations for hundreds of kilometers and that they are often composed of layers large enough to be seen in MOC NA images lends itself rather to speculation that Hellas Planitia materials were deposited in water.

Let us review alternative depositional mechanisms. We disfavor the continental glaciation hypothesis of Kargel and Strom (1992). Such glaciation should have produced large clasts that would be subsequently concentrated on the surface by currently active wind erosion within Hellas. However, a lag of large clasts is inconsistent with the thermal inertia of Hellas Planitia (Moore and Edgett, 1993). Moreover, there is an absence of evidence elsewhere on Mars for the kind of vigorous global hydrologic cycle needed to generate continental style glaciation after early-to-mid Noachian time (Carr, 1996, pp. 123-145). The landforms seen at Viking resolution which Kargel and Strom attributed to glacial scour along the southern periphery of the basin (the Axius Valles region) do not appear to be glacially eroded in MOC NA images (Thomson and Head, 2001). Nor does MOLA data add support to the continental glaciation hypothesis (Thomson and Head, 2001). Both Moore and Edgett (1993) and Tanaka and Leonard 
(McKay et al., 1985), the upper levels of any lakes in Hellas would promptly freeze in most Mars climate scenarios (e.g., Haberle, 1998). Ice covers of water bodies could ultimately thicken to roughly a kilometer because of the low surface temperatures (Moore et al., 1995). The lakes could remain liquid under their ice carapaces on the order of $10^{5}$ years at the latitudes of Hellas, assuming the Martian climate was similar to the present one (Moore et al., 1995). Sublimation would eventually lower water to a level where the ice carapace began to touch bottom. The bottom sediment would initially remain waterlogged, soft and susceptible to deformation by the blocks of grounding ice. Soft sediment deformation on the Earth is characterized as "water-escape structures in unlithified materials" (Lowe, 1975). On the Earth, soft sediment deformation often expresses itself in the form of convolute lamination, dish-and-pillar structures, load casts, and flame structures (e.g., Allen, 1984). The largest of these terrestrial examples typically have meter-scale dimensions. We suggest that soft sediment deformation acted upon the honeycomb and reticulate materials. Though these Martian landforms are twoto-three orders of magnitude larger than terrestrial examples, the observations of convoluted albedo patterns on cell floors and walls, medial laminae along septa crests, and "lips" lining the edges of septa all are consistent with soft sediment deformation (D. R. Lowe, 2001, personal communication). The hectometer to kilometer scale of these features is consistent with formation by ice blocks of this size derived from a kilometer thick carapace. We speculate that the strongly angular hectometer-sized ridge-bounded polygons seen within the kilometer-scale pits of honeycomb terrain may be casts of cracks that were on the undersurface of the grounding ice (Figs. 11 and 12). We speculate further that reticulate terrain's sharp interconnected ridges, which are generally 
However, the greater Hellas depression, as revealed by MOLA, is a region defined by a topographic divide at about the $+1.25 \mathrm{~km}$ elevation that forms a rough circle some $5000 \mathrm{~km}$ in diameter, encompassing an area of $-20 \times 10^{6} \mathrm{~km}^{2}$ (Smith et al., 1999). Material derived both from erosion and from airfalls of various types could be transported by water down gradient within this larger "drainage" basin or "watershed," and could potentially have provided sediment to form the Alpheus Colles plateau as well as the other deposits. In particular, material is inferred to have been transported by water out of the eastern volcanic field by Harmakhis, Reull, Dao, and Niger Valles into the central basin. These large eastern channels have been speculated to have disgorged thick deposits (unit p) at their lowest reaches into the basin (e.g., Crown et al., 1992; Price, 1998), and are evidence for entry into Hellas Planitia of abundant water and the sediment it carried. Tanaka and Leonard (1995) point out that the volcanic materials along the southern periphery of Hellas are deeply and extensively dissected by sinuous valleys (e.g., the Axius Valles region), which are interpreted by them to have been cut by water. Both because of the extent of erosion on these volcanic fields and the volume of material composing Hellas Planitia deposits, we envision that many of these inundations were laden with sediment, more like very muddy water and watery mudflows, than like typical terrestrial rivers. Indeed it may be formally correct to classify some of these flows as watery lahars.

In addition to the channels related to the volcanic fields, many small sinuous channels cut the northern and western landform-defined basin rim (Tanaka and Leonard, 1995), and these presumably served as conduits for material carried to the basin interior. Manifestations of older erosion and drainage may well lie buried under the volcanics of 
speculate that water-laid, then later ice-rich, sediment dominated the geology of the Hellas interior. In our scenario, sediment was transported to the interior by water released by volcanism and other geothermal heat from the Martian crust, then delivered via channels principally east and south of the central basin, perhaps as well as by seepage within the basin from a putative global water reservoir. Layer thicknesses within the observed deposits, especially those of the Alpheus Colles plateau, suggests a high proportion of sediment load to water; perhaps some inundations were more like waterrich low-viscosity mudflows than like typical terrestrial river discharges. The hypothesized water bodies would have developed ice carapaces up to a kilometer thick, assuming that the Martian climate then was similar to that of today. Eventually, as the ice was lost to sublimation, layered deposits were all that remained. The grounding of ice carapaces in some locations (units $r$ and $h$ ) may have formed casts in the initially still-soft sediment. Along the basin periphery, ice margins may have left their marks upon the surface mainly in the form of scarps and marginal deposits. At least one, and possibly several, major water stands are postulated from marginal modifications and sedimentary unconformities occurring at the same topographic elevation all around the basin.

Additional supportive evidence for Hellas Planitia materials having properties consistent with a lacustrine origin comes from thermal and mid-infrared spectroscopic mapping. Moore and Edgett (1993) reported that the Hellas Planitia deposits were probably currently undergoing wind erosion. Thermal inertia of Hellas Planitia indicated that the coarsest material was not larger than sand or a crust-bonded dust (Moore and Edgett, 1993). Thermal inertias for Hellas Planitia derived from very recently acquired Thermal Emission Spectrometer (TES) data (M. T. Mellon, personal communication, 
Planitia are probably a component of erosion-exposed crusts or locally derived detritus (Moore and Edgett, 1993).

Further testing of this hypothesis may be provided by several forthcoming investigations. Comprehensive contiguous stereo imaging of the basin at better than 50 $\mathrm{m} /$ pixel by the Mars Express Orbiter and successor Orbiters, used in conjunction with registered MOLA data, would greatly facilitate a more complete landform analysis. Images at $\sim 10 \mathrm{~cm} /$ pixel from a proposed Mars Reconnaissance Orbiter of clean, and especially differentially eroded, outcrops might reveal process-diagnostic bedding textures and patterns. Near-infrared spectroscopy at $1 \mathrm{~km} /$ pixel or better spatial resolution, $10 \mathrm{~nm}$ or better spectral resolution, and high signal-to-noise could provide additional and perhaps more definitive detection and identification of aqueous minerals and the relationship of aqueous minerals to exposed bedding. Finally, in situ analysis from surface operations should conclusively validate or refute the hypothesis that Hellas once held large lakes.

\section{Acknowledgments}

We are very grateful to Jeff Kargel and especially Ken Edgett for their careful reviews of this paper, which very substantially improved its content and presentation. We are very appreciative of Sam Arriola, Roger Clark, Jim Head, Alan Howard, Bob Kanefsky (and the "click workers"), Don Lowe, Mike Mellon, and Brad Thomson for sharing their work, thoughts, and conversation, all which greatly improved the quality of this study. An initial mapping component of this investigation was funded by NASA's 
Christensen, P.R. 1986. The spatial distribution of rocks on Mars. Icarus 68, 217-238.

Clark, R.N., and T.M. Hoefen 2000. Spectral feature mapping with Mars Global Surveyor thermal emission spectra: Mineralogic implications (abs.). Bull. Amer. Astron. Soc. 32, 1118.

Clifford S.M., and D. Hillel 1983. The stability of ground ice in the equatorial regions of Mars, J. Geophys. Res. 88, 2456-2574.

Clifford, S.M., 1993. A model for the hydrologic and climatic behavior of water on Mars. J. Geophys. Res. 98, 10973-11016.

Clifford, S.M., and T.J. Parker 1999. Hydraulic and thermal arguments regarding the existence and fate of a primordial Martian ocean. In Lunar and Planetary Science XXX, Abstract \# 1619. Lunar and Planetary Institute, Houston (CD-ROM).

Crown, D.A., K.H. Price, and R. Greeley 1992. Geologic evolution of the east rim of the Hellas Basin, Mars. Icarus 100, 1-25.

Damuth, J.E., R.D. Flood, R.O. Kowsmann, R.H. Belderson, and M.A. Gorini. 1988. Anatomy and growth pattern of Amazon deep-sea fan revealed by long-range sidescan sonar (GLORIA) and high resolution seismic studies. Bull. Am. Ass. Petrol. Geol., 72, 885-911.

Fanale, F.P., J.R. Salvail, A.P. Zent, and S.E. Postawko. 1986. Global distribution and migration of sub-surface ice on Mars. Icarus, 67, 1-18. 
Kargel, J.S., V.R. Baker, J.E. Beget, J.F. Lockwood, T.L. Pewe, T.L. Shaw, and R.G. Strom 1995. Evidence of ancient continental glaciation in the Martian northern plains. J. Geophys. Res. 100, 5351-5368.

Keszthelyi, L., and A.S. McEwen. 2001. Terrestrial analogs for Martian volcanic features seen in MOC images. In Lunar and Planetary Science XXXII Abstract \# 1509. Lunar and Planetary Institute, Houston (CD-ROM).

Kieffer, H.H., T.Z. Martin, A.R. Peterfreund, B.M. Jakosky, E.D. Miner, andF.D. Palluconi 1977. Thermal and albedo mapping of Mars during the Viking primary mission. J. Geophys. Res. 82, 4249-4291.

Leonard, G.J., and K.L.Tanaka 2001. Geologic map of the Hellas region of Mars. U.S. Geol. Surv. in press.

Lowe, D.R. 1975. Water escape structures in coarse-grained sediments. Sedimentology 23, 157-204.

Malin, M.C., and K.S. Edgett 1999. Oceans or seas in the Martian northern lowlands: High resolution imaging tests of proposed coastlines. Geophys. Res. Lett. 26, 30493052.

Malin, M.C., and K.S. Edgett 2000a. Rough is smooth and smooth is rough: The Martian surface at meter scale verses hectometer scales and implications for future landing sites. In Lunar and Planetary Science XXXI Abstract \# 1059. Lunar and Planetary Institute, Houston (CD-ROM). 
Moore, J.M., G.D. Clow, W.L. Davis, V.C. Gulick, D.R. Janke, C.P. McKay, C.R. Stoker, A.P. Zent 1995. The circum-Chryse region as a possible example of a hydrologic cycle on Mars: Geologic observations and theoretical evaluation. $J$. Geophys. Res. 100, 5433-5447.

Moore, J.M., and D.E. Wilhelms 2001. Geologic map of part of western Hellas Planitia, Mars. U.S. Geol. Surv., submitted.

Martin, L.J. and R.W. Zurek. 1993. An analysis of the history of dust activity on Mars. J. Geophys. Res. 98, 3221-3246.

Peterfreund, A.R. 1985. Contemporary aeolian processes on Mars: Local dust storms. Ph.D. thesis, 247p., Arizona State Univ., Tempe.

Peterson, J.E. 1977. Geologic map of the Noachis Quadrangle of Mars. USGS map I-910 (MC-27).

Pollack, J.B., R.M. Haberle, J. Schaeffer, and H. Lee. 1990a. Simulations of the general circulation of the Martian atmosphere 1. Polar Processes. J. Geophys. Res. 95, 14471473.

Pollack, J.B., and nine other authors. 1990b. Thermal Emission Spectra of Mars (5.4$10.5 \mu \mathrm{m})$ : Evidence for sulfates, carbonates, and hydrates. J. Geophys. Res. 95, 14,595-14,627.

Potter, D.B. 1976. Geologic map of the Hellas Quadrangle of Mars. USGS map I-941 (MC-28). 


\section{Figures}

Figure 1. Generalized geologic map of the Hellas region. Units are: undifferentiated ancient terrain - u; mantling material - $\mathrm{m}$; plateau material - pl; volcanic material - v; reticulate material - r; plains material - p; channel material- c; sinuous ridges - e; honeycomb material - h. Stratigraphic correlation shown in insert. Geographical features named in text also labeled.

Figure 2. Shaded relief and elevation color-coded topographic map of the Hellas region, generated using MOLA data binned at $1 / 16^{\circ}$. Color elevation scale bars in kilometers. Contour lines indicate locations of several possible stands of ice-covered water: red = $3.1 \mathrm{~km}$; blue $=-5.4 \mathrm{~km}$; yellow $=-5.8 \mathrm{~km}$; white $=-6.9 \mathrm{~km}$. Geomorphic evidence is strongest for the putative stand at about $-5.8 \mathrm{~km}$. Other possible stands are at about -3.1 and $-6.9 \mathrm{~km}$.

Figure 3. Quadrants of the Hellas basin generated from USGS Mars Digital Image Maps $(\mathbf{a}=$ NW quad; $\mathrm{b}=\mathrm{NE}$ quad; $\mathrm{c}=\mathrm{SE}$ quad; $\mathrm{d}=\mathrm{SW}$ quad $)$. White arrows, landforms and deposit contacts associated with the proposed $-5.8 \mathrm{~km}$ stand; black arrows and dashes, landforms and deposit contacts along a putative $-3.1 \mathrm{~km}$ stand; white square dots, change in landscape texture associated with the $-5.4 \mathrm{~km}$ contour; black numbers, locations of Figures 5, 6, 7, 8, 10, 11 and 12; ch, chaos (Sharp, 1973); p, plains material, possibly deposited from Dao and Harmakhis Valles. Possible streamlining from wind erosion may be exhibited by plan form of scarps to right of the white "w"s in Fig. 3a. Elongated knobs which may be yardangs left of white "y"s in Fig. 3d. All maps have been 
covered lake. (MOC narrow angle image M08-03314, centered at $38.3^{\circ} \mathrm{S}, 310.9^{\circ} \mathrm{W}$, image-longitude-centered sinusoidal projection, original resolution $4.2 \mathrm{~m} /$ pixel. North at top. Illumination from left. There is no MOC wide-angle context image for this NA observation. Image processing courtesy Malin Space Science Systems)

Figure 7. Plains material (unit p) exhibiting layers (thin lines in sketch map) in apparent unconformal, contact (arrows, thick line in sketch map) with older unit $m$, now exposed by erosion. Loose dark sand has collected along the base of the contact scarp, forming a marker traceable in context image. The MOC wide-angle context image (M03-05714) was acquired simultaneously with this NA observation. (MOC narrow angle image M0305713 , centered at $30.0^{\circ} \mathrm{S}, 289.8^{\circ} \mathrm{W}$, image-longitude-centered sinusoidal projection, original resolution $1.4 \mathrm{~m} /$ pixel. North at top. Illumination from left. Image processing courtesy Malin Space Science Systems)

Figure 8. View of the bounding scarp (between brackets) of the Alpheus Colles plateau materials (unit pl) exhibiting layers exposed by erosion. Unit pl appears to be overlapped unconformably (black arrow) by younger honeycomb material (unit h), which covers upper half of figure. The MOC wide-angle context image (M10-01314 was acquired simultaneously with this NA observation. (MOC narrow angle image M10-01313, centered at $37.9^{\circ} \mathrm{S}, 303.3^{\circ} \mathrm{W}$, image-longitude-centered sinusoidal projection, original resolution $2.9 \mathrm{~m} /$ pixel. North at top. Illumination from left. Image processing courtesy Malin Space Science Systems)

Figure 9. The three main layers within Alpheus Colles plateau material (unit pl) mappable in Viking images. The oldest ( 1 in sketch map) is degraded; the degradation is 
sinusoidal projection, original resolution $2.8 \mathrm{~m} / \mathrm{p}$ ixel. North at top. Illumination from left. Image processing courtesy Malin Space Science Systems)

Figure 12. High-resolution view within honeycomb material (unit h) showing hectometer-scale ridge-edged polygons that we speculate might be ice-crack casts. (MOC narrow angle image M13-00892, centered at $37.5^{\circ} \mathrm{S}, 305.9^{\circ} \mathrm{W}$, image-longitudecentered sinusoidal projection, original resolution $5.6 \mathrm{~m} /$ pixel. The entire image is shown at left at a reduced scale to illustrate the more typical "honeycomb" appearance of this material. North at top. There is no MOC wide-angle context image for this observation. Illumination from upper left. Image processing courtesy Malin Space Science Systems) 


\section{Fig. 3 a}

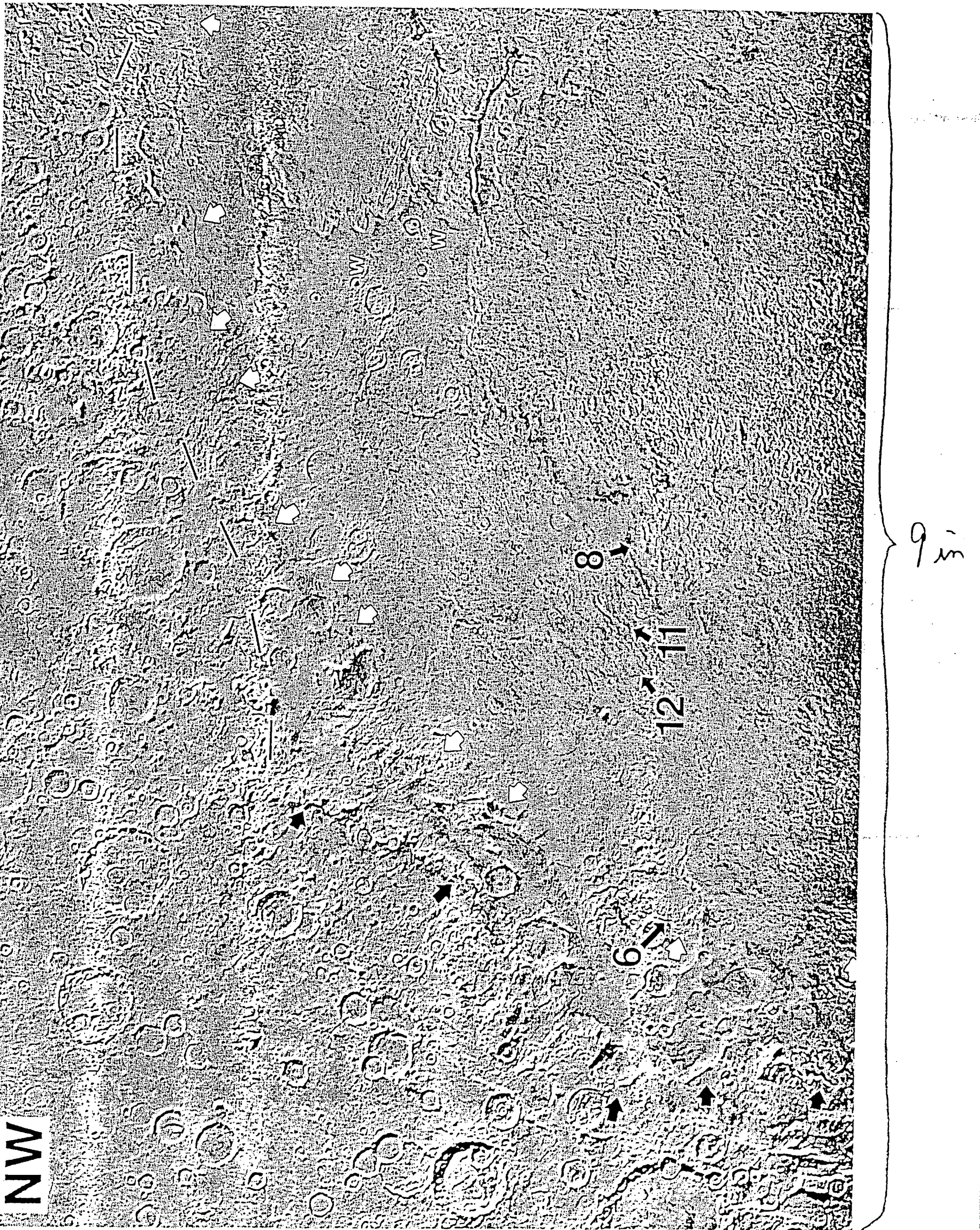




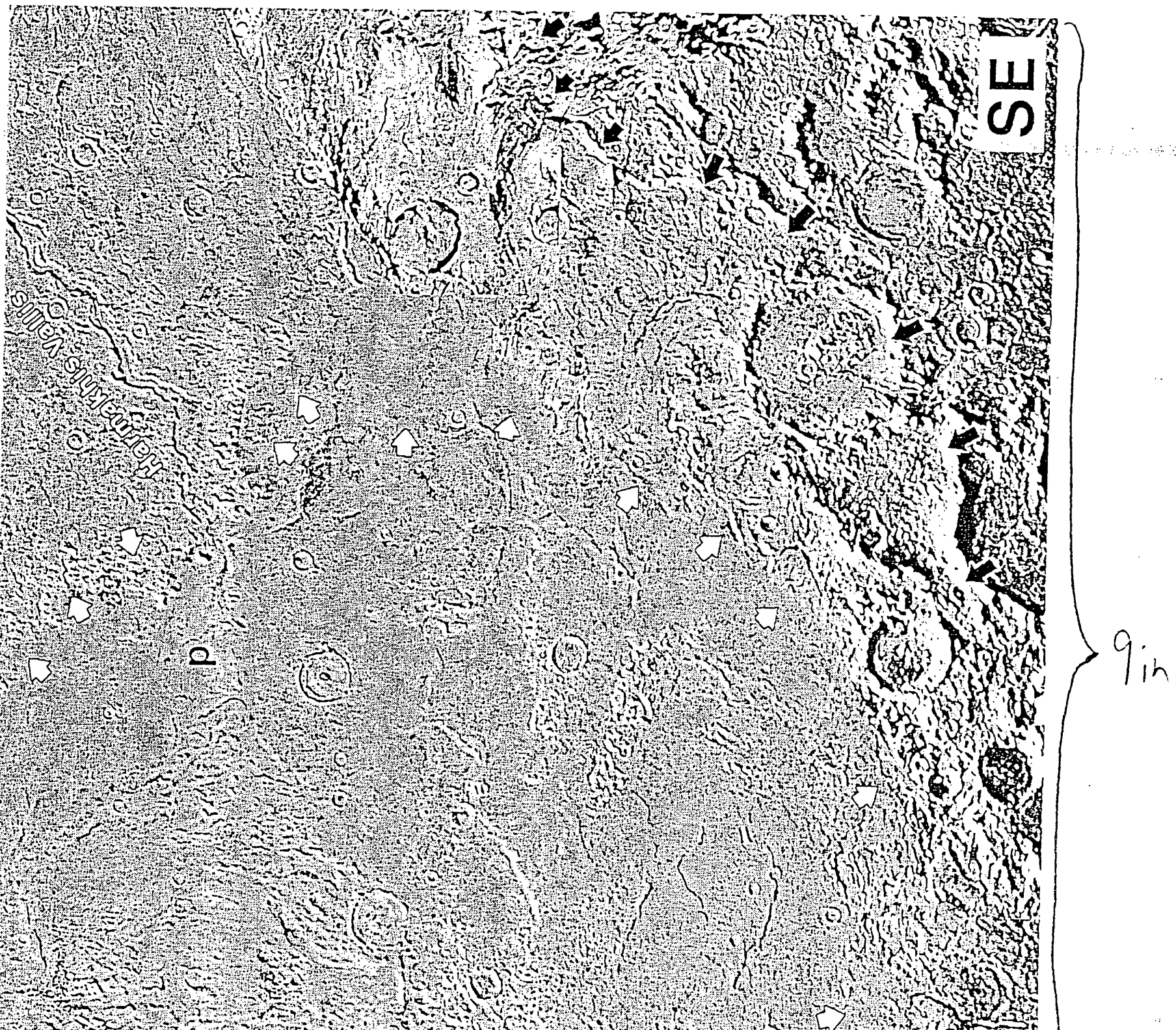

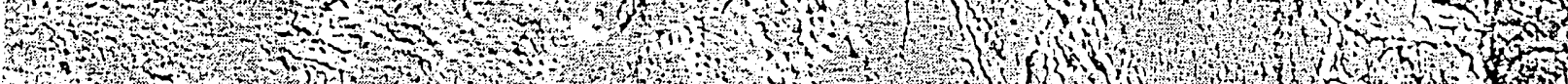

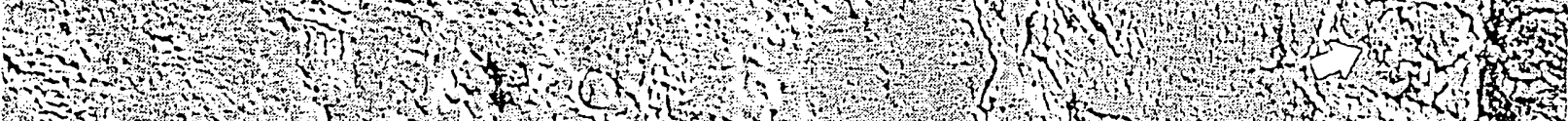
W.

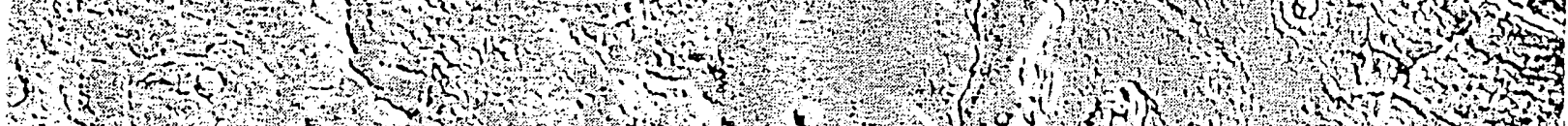

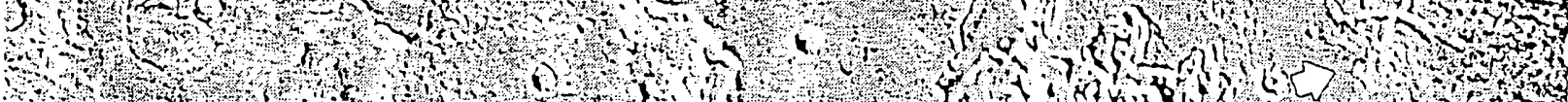

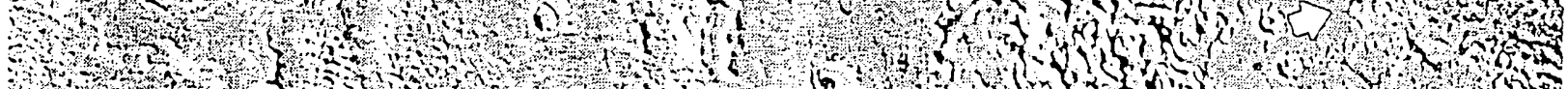
H:2 


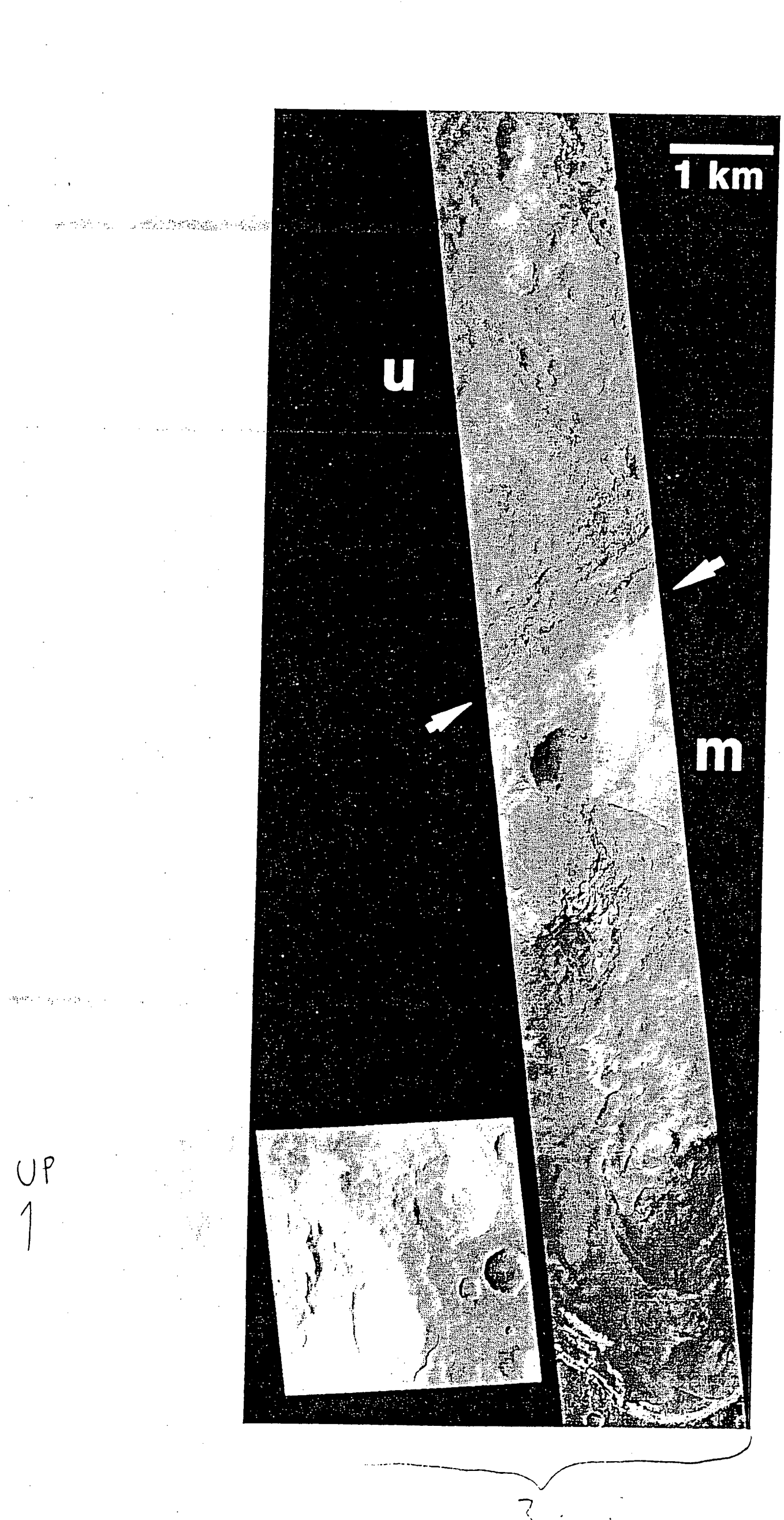

Fig. 4 


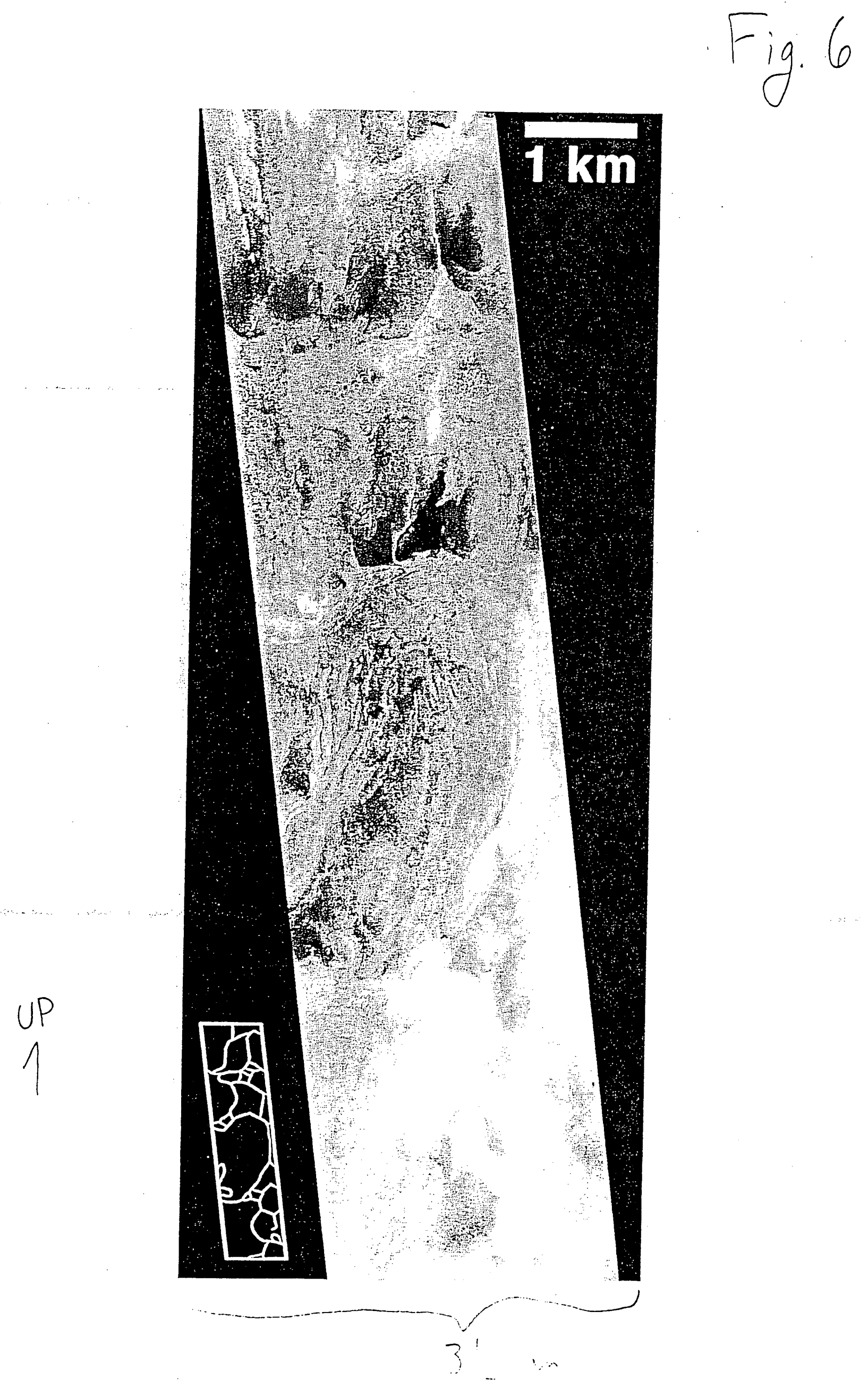




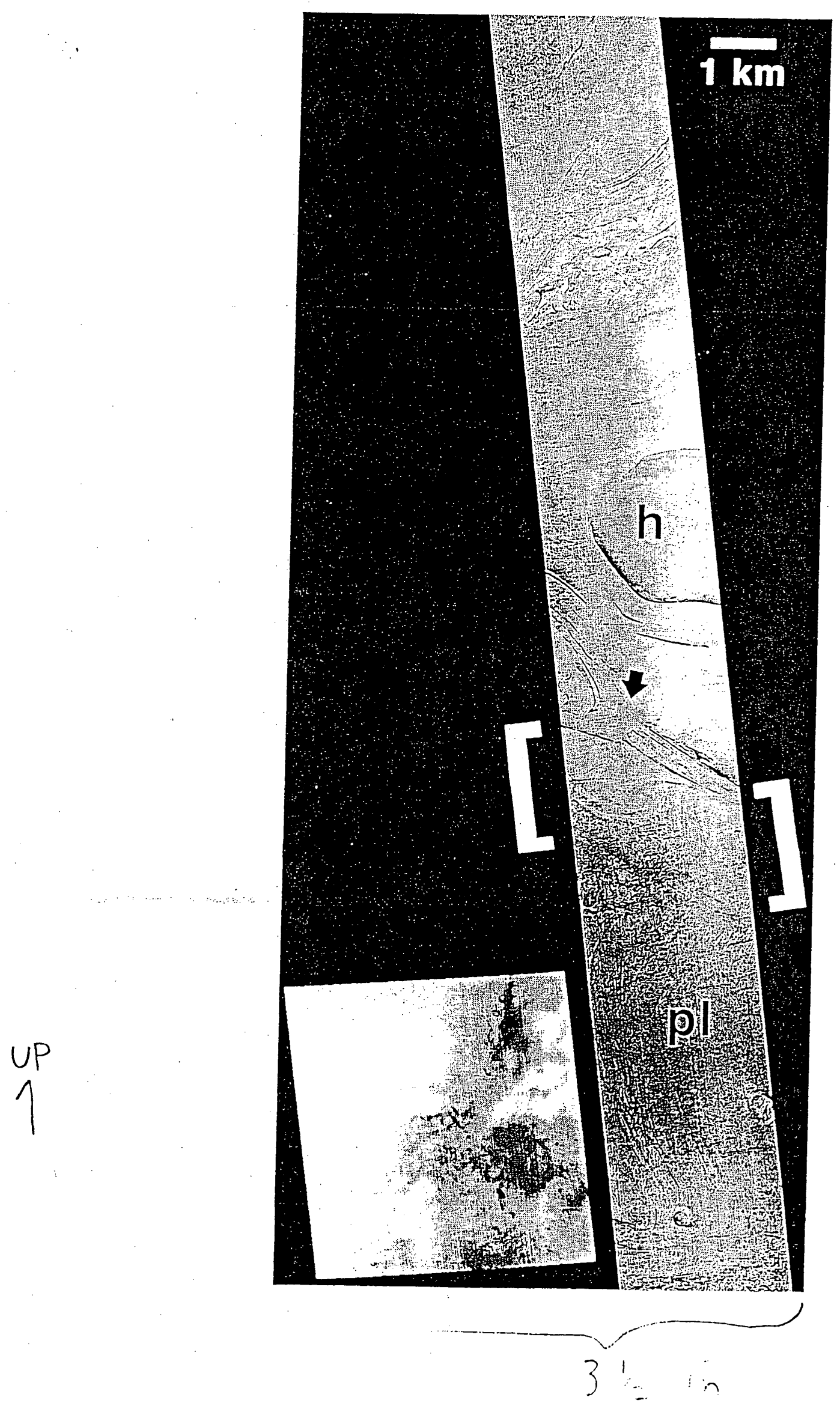


Fig. 10

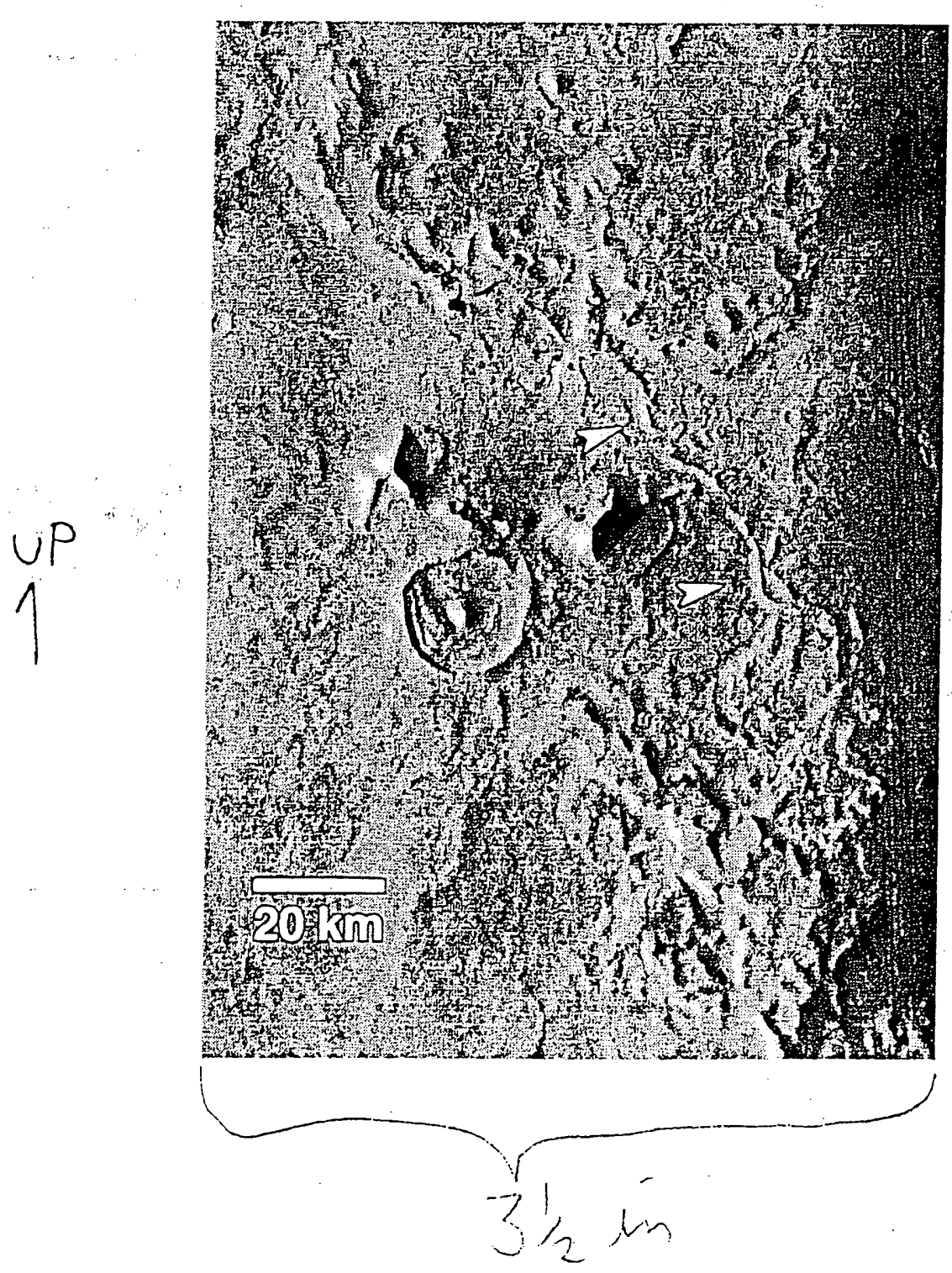




$$
\|
$$


